\title{
Novel Composite Adsorbents Preparation through In Situ Coating and Embedded Regeneration for the Simultaneous Removal of $A s(I I I)$ and $A s(V)$ from Drinking Water
}

\author{
Liu Ruiping ${ }^{1}$, Chang Fangfang ${ }^{1,2}$, Qu Jiuhui ${ }^{{ }^{*}}$, Liu Huijuan ${ }^{1}$ and \\ Zhang Gaosheng ${ }^{1,2}$ \\ ${ }^{1}$ State key Laboratory of Environmental Aquatic Chemistry, Research Center for \\ Eco-Environmental Sciences, Chinese Academy of Sciences, Beijing 100085 \\ ${ }^{2}$ Graduate School, Chinese Academy of Sciences, Beijing 100039
}

\begin{abstract}
This study investigated the effectiveness and mechanisms of a novel composite adsorbent, prepared through in situ coating and regenerated through in situ embedding with Fe-Mn binary oxides onto porous diatomite (FMBO-DE), for the simultaneous removal of As(III) and $\mathrm{As}(\mathrm{V})$ from drinking water.

FMBO-DE was prepared in situ by interactions between equivalent amount of $\mathrm{KMnO} 4$ and FeSO4 (3:1) with suspended porous diatomite. Zeta potential analysis showed the zero point of charge was $\mathrm{pH} 7.0$, slightly higher than Fe-Mn binary oxides (pH 6.1). No X-ray diffraction peaks were observed, confirming that FMBO-DE was amorphous; SEM/EDX analysis showed the surface elemental ratio of $\mathrm{Fe}$ to $\mathrm{Mn}$ was 3:1, indicating that ferric and manganese oxides were evenly homogeneous in Fe-Mn binary oxides.

Kinetics studies showed As was quickly removed by $\mathrm{FMBO}$, up to $80 \%$ of equilibrium capacity within initial 60 minutes. Additionally, it exhibited strong potential for removing both As(III) and $\mathrm{As}(\mathrm{V})$, with maximum adsorption capacities as high as $350 \mathrm{mgAs}(\mathrm{III}) / \mathrm{g}$ FMBO and 200 $\mathrm{mgAs}(\mathrm{V}) / \mathrm{g} \mathrm{FMBO}$, respectively. It was noteworthy that FMBO showed higher potential of removing $\mathrm{As}(\mathrm{III})$ than $\mathrm{As}(\mathrm{V})$.

Continuous column tests demonstrated significant removal of both $\mathrm{As}(\mathrm{III})$ and $\mathrm{As}(\mathrm{V})$. At an initial As concentration of $100 \mu \mathrm{L} \mathrm{L}^{-1}$ and empty bed contact time of $5 \mathrm{~min}$, freshly prepared FMBO-DE could treat 3000 bed volume (BV) of $\mathrm{As}(\mathrm{III})$ and $2000 \mathrm{BV}$ of $\mathrm{As}(\mathrm{V})$ and the effluent As concentration was consistently below $10 \mu \mathrm{g} \mathrm{L}^{-1}$. The in situ embedded regeneration processes obviously increased the capability of removing As from water. After three regenerations, the adsorbing potential was as high as $4500 \mathrm{BV}$ of $\mathrm{As}(\mathrm{III})$ and $3100 \mathrm{BV}$ of $\mathrm{As}(\mathrm{V})$, respectively.
\end{abstract}

Keywords: in situ coating; embedded regeneration; composite adsorbents; arsenic

\section{INTRODUCTION}

Arsenic has been receiving world attention in the past several decades due to its toxicity and carcinogenicity (WHO, 1993; USEPA, 2001). In China, the newly issued National Drinking Water Standard requires that the MCLs level of arsenic being lower than $10 \mu \mathrm{g} \cdot \mathrm{L}^{-1}(\mathrm{PRCMH}$ and PRCSA, 2007).

The objectives of this study were to: i) develop novel adsorbents with oxidizing ability for the simultaneous removal of both $\mathrm{As}(\mathrm{III})$ and $\mathrm{As}(\mathrm{V})$ without oxidants addition; ii) investigate

* Corresponding author. Tel.: +86 10 62849151; fax: +86 10 62923558. E-mail: jhqu@rcees.ac.cn

Water Practice \& Technology Vol 3 No 3 C IWA Publishing 2008 doi: 10.2166/WPT.2008071 
the main characteristics of the novel adsorbents; iii) evaluate the capability of removing arsenic (As(III) and $\mathrm{As}(\mathrm{V}))$ and the mechanisms involved in these processes.

\section{METHODOLOGY}

Generally, the novel adsorbent (FMBO-DE) was prepared through in situ coating the active components of ferric and manganese binary oxides (FMBO) onto porous diatomite (DE), and was regenerated through in situ embedding active species onto the surfaces with adsorbed arsenic. The SEM image of FMBO-DE was presented in Figure 1. Noteworthy, the freshly prepared and regenerated FMBO-DE was directly employed as adsorbents for arsenic removal without further aging and drying.
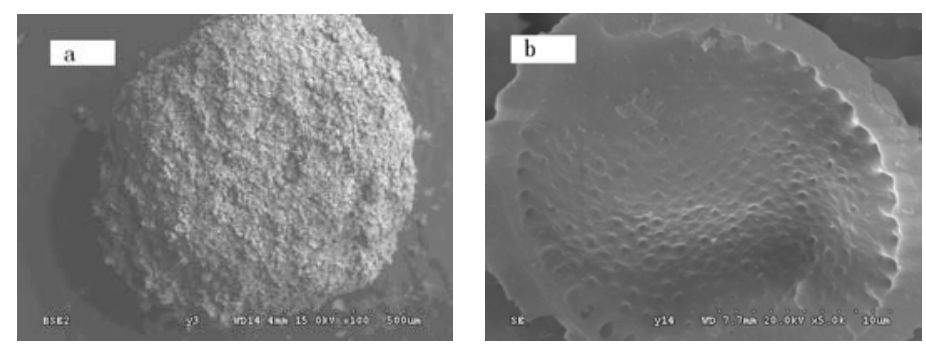

Figure 1: SEM image of FMBO-DE grain $((a) \times 100,(b) \times 5000)$

\section{RESULTS AND CONCLUSIONS Characterization of composite adsorbents}

Zeta potential analysis. The zeta potential of FMBO-DE generally decreased with elevated $\mathrm{pH}$, showing the isoelectric point $\left(\mathrm{pH}_{\mathrm{iep}}\right)$ of $\mathrm{pH}$ 7.0. The zeta potential of FMBO showed similar trends to that of FMBO-DE, except that the $\mathrm{pH}_{\text {iep }}$ was slightly lower to be at $\mathrm{pH6.1}$. The surface potential of FMBO-DE was mainly determined with that of FMBO, rather than that of diatomite.

$X R D$ characterization of FMBO. No obvious peaks were observed by X-ray diffraction (XRD) analysis for FMBO, which confirming that the adsorbents prepared through the procedures noted above was amorphous. The in situ prepared amorphous adsorbents exhibited high surface area and much surface hydroxyl groups, which was of critically importance for arsenic adsorption (Zhang, G.S. et al., 2007a).

SEM/EDX analysis. SEM/EDX analysis indicated that $\mathrm{Si}, \mathrm{O}$ and $\mathrm{C}$ were the main elements for plain diatomite (Figure 2a). FMBO-DE showed obvious peaks of elemental $\mathrm{Fe}$ and $\mathrm{Mn}$, demonstrated the presence of ferric oxides and manganese oxides on the surface (Figure $2 b$ ). Additionally, it was observed that the surface elemental ratio of $\mathrm{Fe}$ to $\mathrm{Mn}$ was 3:1 for FMBO-DE, indicating that ferric oxides and manganese oxides were evenly homogeneous.

\section{Arsenic removal potential evaluation and environmental effects}

Arsenic removal kinetics. Kinetics studies showed that both As(III) and As(V) was quickly removed by FMBO-DE, and the removing capacity reached to $80 \%$ of equilibrium capacity within the initial 60 minutes. 

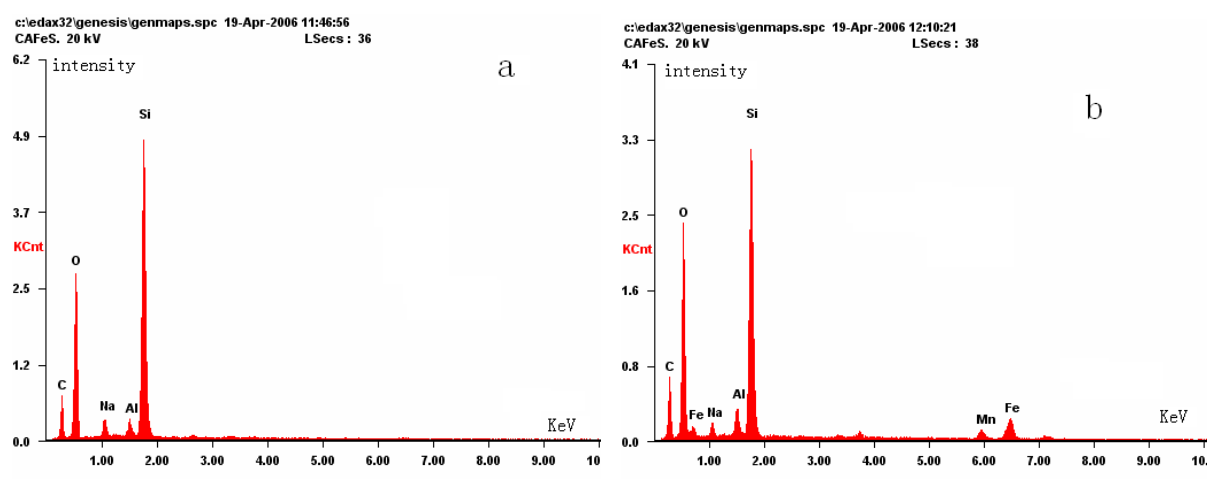

Figure 2: Energy dispersive X-ray analysis of (a) plain diatomite, (b) FMBO-DE

Adsorption capacity for $A s(I I I)$ and $A s(V)$. Adsorption isotherms analysis demonstrated that FMBO-DE exhibited strong potential of removing both As(III) and As(V). The maximum adsorption capacities were as high as $350 \mathrm{mgAs}(\mathrm{III}) / \mathrm{g}$ FMBO and $200 \mathrm{mgAs}(\mathrm{V}) / \mathrm{g}$ FMBO as $\mathrm{Fe}$ and $\mathrm{Mn}$, respectively. It was interestingly observed that FMBO-DE showed remarkably higher potential of removing As(III) than $\mathrm{As}(\mathrm{V})$. Our research group has reported similar results for FMBO, which had been aged and dried before employed as adsorbents for arsenic removal, and the mechanisms involved in these processes had also been well investigated (Zhang, G.S. et al., 2007a; Zhang, G.S. et al., 2007b).

Effects of $\mathrm{pH}$ on arsenic removal. FMBO-DE exhibited good potential of removing As(III) and $\mathrm{As}(\mathrm{V})$ in relatively high $\mathrm{pH}$ ranges of $\mathrm{pH} 4.0 \sim 8.0$, showing maximal adsorption capability as near $\mathrm{pH} 5.5$ for both $\mathrm{As}(\mathrm{III})$ and $\mathrm{As}(\mathrm{V})$. The elevated $\mathrm{pH}$ led to more negatively charged surfaces, which inhibiting the interaction between FMBO surfaces and anionic arsenic species.

Effects of coexistent ions on arsenic removal. The effects of coexistent ions as carbonate, phosphate, sulphate, nitrate, silicate, chloride ion, fluoride ion, calcium ion, and magnesium ion on arsenic removal had been investigated at ion concentration of $1.0 \mathrm{mmol} \cdot \mathrm{L}^{-1}$. Phosphate and silicate showed significant inhibiting effects of decreasing removal potential for As(III) and $\mathrm{As}(\mathrm{V})$. Carbonate also slightly decreased arsenic adsorption onto FMBO-DE. Other coexistent species had negligible effects on arsenic removal with FMBO-DE. These results were in accordance with what had been noted before (Liu et al., 2007; Meng et al., 2000). Additionally, more remarkable side effects were observed at more acidic $\mathrm{pH} 3.6$ than at near neutral $\mathrm{pH}$ of $\mathrm{pH} 6.0$ for both phosphate and silicate.

\section{Bench scale column tests for arsenic removal and adsorbents regeneration}

Continuous column tests also demonstrated the strong capacity of removing both As(III) and $\mathrm{As}(\mathrm{V})$ (Figure 3). At the initial arsenic concentration of $100 \mu \mathrm{g} \mathrm{L} \mathrm{L}^{-1}$ and empty bed contact time (EBCT) of $5 \mathrm{~min}$, the freshly-prepared FMBO-DE can respectively treat 3000 bed volume (BV) of $\mathrm{As}(\mathrm{III})$ and $2000 \mathrm{BV}$ of $\mathrm{As}(\mathrm{V})$ to achieve the effluent arsenic concentration being consistently below $10 \mu \mathrm{g} \mathrm{L}^{-1}$. Moreover, the in situ embedded regeneration processes would not decrease, but obviously increased the capability of removing both As(III) and As(V) from water. After repeating 3 circles of arsenic adsorption and adsorbents regeneration, the adsorbing potential increased to as high as $4500 \mathrm{BV}$ of $\mathrm{As}(\mathrm{III})$ and $3100 \mathrm{BV}$ of $\mathrm{As}(\mathrm{V})$, respectively. 

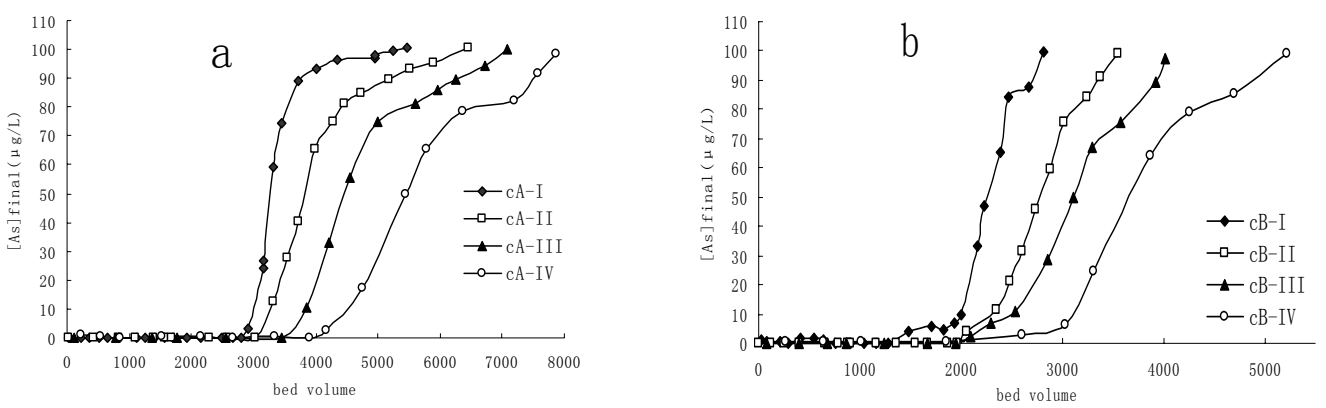

Figure 3: Arsenite (a) and arsenate (b) breakthrough curves for FMBO-DE column regenerated through in situ embedding $\left(\mathrm{pH}=7.0,[\mathrm{As}]_{0}=100 \mu \mathrm{g} \mathrm{L}{ }^{-1}, \mathrm{EBCT}=5 \mathrm{~min}\right)$

Furthermore, it was demonstrated that the higher capability of removing arsenic was ascribed to higher BET surface areas and more Fe-Mn binary oxides coated after in situ embedded regeneration (Table 1).

Table 1: Summary of the characteristics of FMO-DE packed in column A and plain Porous diatomite

\begin{tabular}{ccccc}
\hline sample & $\begin{array}{c}\text { Surface area } \\
\left(\mathrm{m}^{2} \mathrm{~g}^{-1}\right)\end{array}$ & $\begin{array}{c}\text { Pore volume } \\
\left(\mathrm{mL} \mathrm{g}^{-1}\right)\end{array}$ & $\begin{array}{c}\text { Average pore } \\
\text { diameter }(\AA)\end{array}$ & $\begin{array}{c}\text { Fe and Mn content } \\
\left(\mathrm{mg} \mathrm{g}^{-1}\right)\end{array}$ \\
\hline Plain DE & 7.0866 & 0.0050 & 18.1292 & 0.0 \\
cA-I & 8.6632 & 0.0126 & 58.2454 & 10.58 \\
cA -II & 10.7284 & 0.0149 & 61.5657 & 16.40 \\
cA -III & 12.5079 & 0.0206 & 65.7307 & 22.61 \\
cA -IV & 16.2295 & 0.0209 & 69.5322 & 29.74 \\
\hline
\end{tabular}

\section{ACKNOWLEDGEMENTS}

This work was supported by the Funds for Creative Research Groups of China (Grant No. 50621804) and the National Natural Science Foundation of China (Grant No. 50608067).

\section{References}

Liu, R.P., Qu, J.H., Xia, S.J., Zhang, G.S. and Li, G,B. (2007) Silicate Hindering Ferric Hydroxide Precipitation: Inhibiting Arsenic Removal From Water. Environ. Engineer. Sci., 24(5), 709-717

Meng, X.G., Bang, S., and Korfiatis, G. P. (2000) Effects of Silicate, Sulfate, and Carbonate on Arsenic Removal by Ferric Chloride. Wat. Res., 34 (4), 1255-1261.

Ministry of Health of P.R.China and Standardization Administration of P.R.China. (2007) Sanitary Standard for Drinking Water (GB5749-2006)

USEPA (2001) Rules and regulations national primary drinking water regulations: arsenic and clarifications to compliance and new source contaminants monitoring. Federal Register, 66(14): 6976-7066

WHO (1993) Guidelines for drinking-water quality. Vol. 1: Recommendations, $2^{\text {nd }}$ ed., WHO, Geneva.

Zhang, G.S. Qu, J.H. Liu, H.J. Liu, R.P. and Li, G.T. (2007) Removal mechanism of As (III) by a novel Fe-Mn binary oxide adsorbent: Oxidation and sorption. Environ. Sci. Technol. 41, 4613-4619

Zhang, G.S., Qu, J.H., Liu, H.J., Liu, R.P. and Wu, R.C. (2007) Preparation and evaluation of a novel Fe-Mn binary oxide adsorbent for effective arsenite removal. Wat. Res., 41(9), 1921-1928. 